\title{
Ocular Hypertension: A Review And Evidence-Based Roadmap
}

\author{
Andrew John Rixon \\ OD, FAAO \\ Residency Coordinator \\ Memphis VAMC
}

\begin{abstract}
Increased intraocular pressure is arguably the most important, and currently the only modifiable, risk factor for glaucomatous optic neuropathy. Ocular hypertension is often encountered by clinicians in daily practice and is expected to be seen with increasing frequency as the population ages. Awareness and understanding of the extensive research performed on this subject, with particular focus on the work of the Ocular Hypertension Study Group, are critical for comprehensively assessing the risk of conversion to glaucoma. Although management decisions can be complex, they can be aptly handled by the well-informed optometrist in consultation with their patients.
\end{abstract}

\section{KEY WORDS:}

ocular hypertension $(\mathrm{OH})$, primary open angle glaucoma $(\mathrm{POAG})$, central corneal thickness (CCT), ocular hypertension study (OHTS), number needed to treat (NNT), decision-support tools, threshold to treat

he primary goals of the optometrist are to prevent disease and to maintain and maximize visual health and function. Glaucomatous optic neuropathy is the leading cause of irreversible blindness worldwide; the current global prevalence of glaucoma in persons between 40 and 80 years of age is $3.54 \%$, or approximately 64.3 million individuals. ${ }^{1}$ As the population continues to simultaneously increase and age, this number is expected to increase to 76.0 million by 2020 and to a staggering 111.8 million by $2040 .{ }^{1}$ Specifically in Canada, it was estimated that 409,000 people had glaucoma in 2002-2003. ${ }^{2}$ The National Coalition for Vision Health has predicted a 105\% increase in the number of Canadians who will be rendered blind as a result of glaucoma, from 9,500 cases in 2006 to 19,400 cases by $2031 .^{2}$ This disease imposes a substantial burden on both the individual and society as a whole, but it can be combated by the application of optometry. Although our understanding of glaucomatous optic neuropathy continues to expand, increased intraocular pressure (IOP) remains the most important modifiable risk factor for this optic neuropathy. ${ }^{3}$ As a result, substantial energy has been devoted to research on ocular hypertension $(\mathrm{OH})$. Historically, $\mathrm{OH}$ was considered to be synonymous with glaucoma, or a patient was automatically considered to be in a "glaucoma suspect" category, ${ }^{4,5}$ At present, $\mathrm{OH}$ is defined as an IOP greater than 2 standard deviations from the mean of a normal adult population, with "normal" visual fields and a "normal" optic disc structure.6 According to Armaly, "normal" IOP, based on Goldmann applanation tonometry (GAT), is expected to be $16 \pm 2.5 \mathrm{mmHg}$. According to this distribution, approximately $95 \%$ of the population would be expected to have an IOP under $21 \mathrm{mmHg}$ and $98 \%$ would have an IOP under $24 \mathrm{mmHg}$. However, these are statistical averages based on the presumption of a symmetrical Gaussian distribution. In actuality, studies have shown that IOP in a population is not distributed symmetrically, but rather is skewed toward higher pressure..$^{8-11}$ The fact that the distribution curve is skewed cannot be regarded as evidence that eyes with IOP above a statistical normal have a pathological process. ${ }^{12}$ Accordingly, there is some uncertainty regarding the influence of statistically high IOP in individual patients. It is critical that the optometric community have a strong understanding of the prevailing evidence on $\mathrm{OH}$ to reduce this uncertainty. 
EPIDEMIOLOGY OF OH

Fortunately, most patients with $\mathrm{OH}$ do not develop glaucoma. An analysis of multiple studies shows that the 5-year incidence of primary open-angle glaucoma (POAG) in untreated ocular hypertensive cases ranges from 9.5 to $22 \% .^{13}$ In contrast, the 5-year incidence of POAG in treated ocular hypertensive patients ranges from 4.4 to $15 \%$, which represents a substantial reduction over that in untreated patients. Although this analysis suggests that the overall incidence of glaucoma development is low, the visual and functional consequences in patients who actually develop glaucoma can be devastating. When deciding upon whether or not to treat, it is helpful to understand the prevalence of $\mathrm{OH}$ in various populations, and thus the potential impact of therapeutic intervention. General estimates of the overall prevalence of ocular hypertension have been reported to range from 4 to $7 \%$ of the US population over age 40, and this prevalence increases with age..$^{14}$ Thus, an estimated 4.8 to 9.5 million people in the US have elevated IOP without detectable glaucomatous damage using current clinical tests. ${ }^{15}$ The variation in prevalence can be even greater when specific populations are examined. For example, the prevalence of ocular hypertension ranged from $2.3 \%$ in patients $43-49$ years of age to $7.7 \%$ in those 75-79 years of age in the widely cited Beaver Dam Study, which included a primarily Caucasian population in Wisconsin, USA. ${ }^{16}$ In a study with similar demographics, the Blue Mountain Eye Study, which included an older Australian community of largely white subjects of northern European descent, the age-standardized prevalence of $\mathrm{OH}$ was $5.15 \%$ in patients aged 50 and older in the year $2000 .{ }^{17}$ The authors projected that the prevalence in this population would reach $5.48 \%$ in the year 2030. ${ }^{18}$ In the Los Angeles Latino Eye Study, in Latinos from California, the 4-year incidence of OH, defined as IOP $>21 \mathrm{mmHg}$ and the absence of optic disc damage or abnormal visual field results, was 3.6\%, after adjusting for the age distribution..$^{19}$ The Chennai Eye Disease Incidence Study, in a population of Southern Indians aged 40 and older, found that the 6-year incidence of ocular hypertension, defined as IOP above the $97.5^{\text {th }}$ percentile of the population with no evidence of glaucoma, was $2.17 \%{ }^{20}$ Thus, the epidemiology of $\mathrm{OH}$ varies widely among different specific populations and the impact of treatment may be greater in some communities than others.

OH HISTORICAL PERSPECTIVE

The general opinion in 1862, dating back to Donders, was that ocular hypertension nearly always progressed with increasingly higher IOPs, and was synonymous with glaucoma. ${ }^{4}$ This viewpoint persisted into the late 1950s. By the 1960 s, it had become increasingly obvious that the observed prevalence of glaucoma, defined by the stricter criteria of raised pressure, cupped disc, and field loss, was too low to support the hypothesis that pressures beyond the higher end of the Gaussian distribution inevitably led to glaucoma. ${ }^{21}$ Although this observation was innovative, it was still not clear whether IOP in patients with $\mathrm{OH}$ would continue to rise over time or how often ocular hypertension was a precursor of manifest glaucoma. A 1964 study by Linner and Stromberg on untreated ocular hypertensives determined that IOP in these patients did not tend to rise over time or show signs of glaucoma. ${ }^{4}$ In 1968, Graham reported a follow-up study of 232 ocular hypertensives over 43 months, and only 1 patient developed a field defect. ${ }^{22}$ In 1969, in a 10-year study on subjects at all levels of tension, Armaly found that patients with initial applanation readings $>23 \mathrm{mmHg}$ had a very low incidence of visual field loss, although there was, not surprisingly, a tendency for field defects to be more prevalent at higher pressures. ${ }^{23}$ Multiple small retrospective studies on $\mathrm{OH}$ were performed over the next few decades. ${ }^{24-32}$ The results of these studies were inconclusive; some demonstrated that treatment was effective and others demonstrated that treatment was not effective for slowing the conversion to glaucoma. Problematically, these studies had no consistent definition of glaucoma, were limited by poorly efficacious medications, and used varying end points. As a result of the conflicting methods, definitions, and findings, these studies prevented the attainment of a consensus that would be useful to clinicians in their treatment decisions. Furthermore, it was unclear whether the benefits of treatment outweighed the risks associated with treatment..$^{33}$ In an effort to finally achieve a consensus on the management of these patients, the landmark Ocular Hypertension Treatment Study (OHTS) was initiated in 1994.

OCULAR HYPERTENSION TREATMENT STUDY

Specifically, OHTS sought to evaluate the safety and efficacy of topical ocular hypotensive medication in preventing or delaying the onset of visual field loss and/or optic nerve damage in subjects with ocular hypertension who were at moderate risk for developing primary open angle glaucoma. ${ }^{34}$ OHTS was a multicenter; convenience randomized controlled trial (RCT) involving 1,636 ocular hypertensive patients who were at moderate risk for developing glaucoma. Demographically, $69 \%$ of the participants were Caucasian, 25\% were African-American and $3.6 \%$ were of Hispanic origin. Strict eligibility criteria were required for participation. Patients were randomized to a treatment group or a close observation group. The goal in the treatment group was to achieve an IOP reduction of $20 \%$ or more from baseline and to reach an IOP level under $24 \mathrm{mmHg}$. The study was split into two phases. Phase I had a mean duration of 72 months. At 60 months, the cumulative probability of developing clinically detectable glaucoma, defined as reproducible visual field abnormali- 
ties or reproducible clinically significant optic disc deterioration attributable to glaucoma, was $4.4 \%$ in the medication group and $9.5 \%$ in the observation group. ${ }^{33}$ Based on the greater than $50 \%$ relative risk reduction and the absolute risk reduction of $5.1 \%$ in the treatment group, the authors concluded that the use of medications was clearly effective in delaying or preventing the onset of POAG in individuals with $\mathrm{OH}$. These results, however, failed to answer many critical questions that could assist the clinician in decision-making when assessing these patients.

Phase II of OHTS aspired to determine whether all patients should be treated, when they should be treated, and specifically whether there was a penalty to delaying treatment. All participants from phase I were invited to participate in phase II, and 1,366 patients continued in the study. Ocular hypotensive therapy was started in the original observation group, and the original treatment group continued their medications. Phase II lasted for a mean of 5.5 years and included 1,159 active patients at the study's 13-year end point. ${ }^{15}$ This created a delayed treatment group to compare to the so-called early treatment group. After 13 years, the overall percentage of patients who were initially randomized to the observation group that developed POAG was $22 \%$, compared with $16 \%$ in the original treatment group, which means that treatment was associated with a $27 \%$ relative reduction in the incidence of POAG. ${ }^{15}$ Glaucoma was detected at a median of 6.0 years in the observation group and 8.7 years in the treatment group. ${ }^{15}$ These overall 13-year outcomes further validated phase I, and reinforced the value of treatment in delaying or preventing glaucoma. In addressing whether there was a penalty to delaying treatment, the authors concluded that there was only a modest overall penalty. This was rooted in the fact that the 13-year incidence of POAG decreased substantially in patients from the observation group once medication was initiated in phase II. The cumulative proportion of participants who developed POAG in phase II was $11 \%$ in the original observation group and $12 \%$ in the original medication group, which was an incremental difference. They suggested that this result indicates that there is no acceleration of damage if treatment is initially withheld, since the frequency of developing the disease clearly did not increase once treatment was initiated. However, they did note that there was a greater

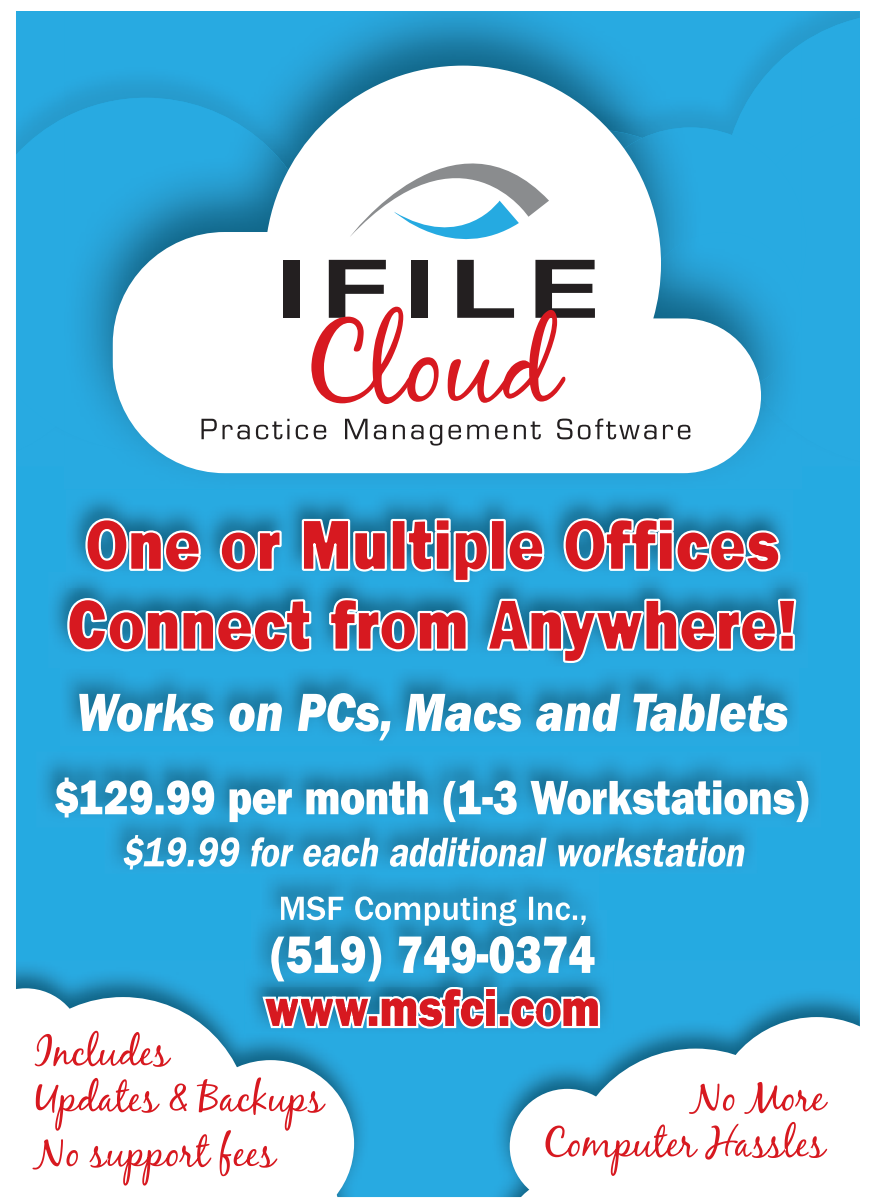


disease burden on the original observation group, with more eyes reaching the end points regarding both glaucomatous optic disc and visual field ( $8 \%$ observation vs $5 \%$ treatment), the development of bilateral glaucoma ( $6 \%$ observation vs $4 \%$ treatment), and a significantly worse pattern standard deviation (PSD) slope. ${ }^{15}$

A more detailed analysis established risk subgroups that were divided into tertiles of low, moderate and high risk. These subgroups had baseline predicted 5-year risks of developing POAG of $\leq 6 \%$, between 6 and $13 \%$, and $\geq 13 \%$, respectively. The 13-year results showed that the incidence of POAG in the lowest-risk subgroup was $8 \%$ in the observation group and $7 \%$ in the treatment group, which reflects a simplified relative risk reduction (RRR) of approximately $12.5 \%$ and an absolute risk reduction (ARR) of 1\%. In the moderate-risk subgroup, 19\% of patients in the original observation group developed POAG versus $14 \%$ in the treatment group; a RRR of $26 \%$ and an ARR of $5 \%$. In the highest-risk subgroup, $40 \%$ of patients in the observation group and $28 \%$ in the treatment group developed POAG; a RRR of $30 \%$ and an ARR of $12 \%{ }^{15}$

The authors concluded that the 13-year results showed that high-risk $\mathrm{OH}$ patients might benefit from more frequent follow-up examinations and earlier treatment, while treating the lowest-risk $\mathrm{OH}$ patients provided little value: these patients required less-frequent clinical evaluation and would not suffer from delayed treatment. They also suggested that if, in fact, there was little harm to delaying treatment, with no increased incidence of the disease once treatment was initiated, then watchful waiting could be another viable option in all patients. Unfortunately, they could not provide specific guidance on what constituted watchful waiting, since long-term functional consequences were unknown. They estimated that this question could be answered with an additional 5-20 years of follow-up. ${ }^{15}$

Phase II determined that patients in the observation group had a significantly worse PSD slope. This result had limited influence, however, since change was defined based on how follow-up visual field results differed compared to those in an age-matched normal, which is known as an event analysis. ${ }^{36}$ Visual field testing exhibits both intra-test and inter-test variability of between 2 and $3 \mathrm{~dB}$, which can undermine the correct interpretation of the patient's visual status ${ }^{37}$ The $^{\text {' }}$ OHTS investigators originally defined a visual field abnormality as 2 consecutive abnormal fields with the abnormality in the same location and on the same index, believing this to be sufficient to detect meaningful change. ${ }^{34}$ Under this initial criterion, a staggering $86 \%$ of first-occurring abnormal visual fields were not confirmed on the next retest. ${ }^{38}$ This illustrates the inherent difficulty in confirming a meaningful visual field abnormality with limited testing using a test with known variability. This result obviated the fact that the initial abnormality criterion was unacceptable, prompting the investigators to change the criterion for abnormality to a more stringent requirement of 3 consecutive abnormal fields with the abnormality in the same location and on the same index. ${ }^{38}$ Although the revised OHTS visual field abnormality criterion countered the fluctuation in testing, thus providing more repeatable and meaningful data, the study's use of an event analysis to confirm change had its disadvantages. The limitations of an event analysis include the underutilization of many intervening VF tests when determining if change has occurred and the lack of an estimated rate of change. ${ }^{36} \mathrm{~A}$ better indicator of change, known as a trend analysis, tracks intra-subject, longitudinal variability of specific visual field points or the entire field itself. ${ }^{39}$ De Moraes et al. ${ }^{39}$, in a follow-up OHTS publication, used a trend analysis to compare the rate of visual field change before and after the initiation of treatment in patients who were originally assigned to observation. Treatment decreased the global visual field mean deviation rate of change by $74 \%$ and the localized rate of change by $53 \%$. The benefit of treatment extended both to patients who converted to POAG and those who did not. The authors noted that the rate of change in patients who converted to glaucoma was still significant and suggested that the target IOP be adjusted more aggressively in these patients than when they were classified simply as ocular hypertensives.

Although the OHTS had a tremendous impact on our understanding of these patients, the authors noted some limitations to the study:

1. The target of a $20 \%$ reduction in IOP was not considered to be ideal; it was simply realistic for the medications that were available at the start of the study. It is conceivable that the percent risk reduction would have been even greater in the treatment group if a more aggressive target had been set and achieved.

2. OHTS was not designed to be an assessment of ocular hypertension in the general population. This was a convenience study involving healthy volunteers and is not generalizable to patients who do not have baseline characteristics similar to those in the OHTS subjects.

3. The threshold for diagnosing POAG was very high given the available diagnostic techniques at the time.

4. One-third of OHTS participants were considered to be high-risk based on the strict criterion of IOP of 24- 
$32 \mathrm{mmHg}$ in the higher study eye..$^{15}$ The authors speculated that most of the general public with OH likely have lower IOPs than this criterion, and consequently have a lower risk profile than the patients involved in the study. The two phases of this very well-controlled study definitively showed that early treatment of patients with high-risk ocular hypertension successfully delayed or prevented the development of glaucoma, whereas early treatment of low-risk patients was of little value.

IMAGING IN OH PATIENTS

Trends in the diagnosis and management of glaucoma show a substantially increased reliance on objective imaging of the optic disc, retinal nerve fiber layer and ganglion cell complex, with a concurrent decreased reliance on visual field testing. ${ }^{40}$ When OHTS began, these imaging capabilities were not readily available, and structural glaucoma changes were determined by comparing stereoscopic disc photographs. One of the first commercially available technologies that could objectively assess the optic disc and retinal nerve fiber layer was the confocal scanning laser ophthalmoscope (CSLO), specifically the Heidelberg Retinal Tomogram (HRT). In a prospective, ancillary study to OHTS, the investigators sought to determine, using the HRT, whether optic disc topographic measurements are an accurate predictor of visual field loss, as well as how effective the CSLO is in detecting the presence and progression of glaucomatous optic disc damage..$^{41}$ The study revealed that multiple baseline optic nerve head parameters were significantly associated with the development of glaucomatous disc or visual field damage. ${ }^{42}$ Specifically, the baseline Glaucoma Probability Score (GPS), Moorfields Regression Analysis (MRA) and stereometric parameters showed similar predictive abilities as models using the photograph-based horizontal cup-to-disc ratio. ${ }^{43}$ The study also compared the rate of structural change in $\mathrm{OH}$ patients who developed glaucoma to that in those who did not. The authors found that the rate of rim area loss in patients who developed glaucoma was five times faster than that in those who did not develop glaucoma. ${ }^{44}$ Although this study only involved CSLO technology, it is reasonable to conclude that other forms of objective imaging technology may play a significant role in both helping to predict who is at risk for developing glaucoma and how a practitioner can view the rate of change when ascertaining that the patient is converting to POAG.

Optical coherence tomography (OCT), which was not commercially available at the time of OHTS recruitment, is now ubiquitous in glaucoma management and can be used to detect disease years prior to repeatable visual field loss. Kuang et al. ${ }^{45}$ investigated the estimated lead time gained by retinal nerve fiber layer (RNFL) measurements using OCT for detecting glaucoma prior to the development of VF loss in glaucoma suspects. They estimated that up to $35 \%$ of eyes have an abnormal average RNFL thickness 4 years before the development of visual field loss and 19\% of eyes have an abnormal RNFL thickness 8 years before visual field loss. Incredibly, these results are consistent with the finding by Sommer et al. ${ }^{46}$ in 1991 that $60 \%$ of studied glaucoma eyes had photographically detectable nerve fiber defects 6 years before the development of glaucomatous field defects. Although the OHTS ancillary study was performed with CSLO technology, RNFL assessment with OCT has now been shown to be superior to CSLO for detecting pre-perimetric glaucomatous damage in glaucoma suspects. ${ }^{47}$ Colombo et al. ${ }^{48}$, in a study of 68 untreated ocular hypertensives, assessed the correlation between the 5-year risk of developing glaucoma and the condition of the optic nerve head and retinal nerve fiber evaluated by OCT, scanning laser polarimetry and CSLO. They found significant correlations between OCT RNFL parameters and an individual's risk to develop POAG that did not exist with the other two technologies. Multiple smaller studies have determined that either mean RNFL or segmental RNFL measurements are thinner in $\mathrm{OH}$ patients than in normals. However, these studies did not demonstrate any uniform OCT parameters that might reliably predict the development of early glaucoma in OH patients. ${ }^{49-55}$ Since OCT is superior to CSLO, it would be interesting to see the predictive capability of OHTS ancillary imaging if OCT had been available and used in that study. Additionally, although the sensitivity and repeatability of OCT technology is indisputable, the fact that Sommer et al. achieved results similar to those of Kuang et al. 24 years earlier reinforces the notion that photographic assessment of the retinal nerve fiber layer is a powerful tool that should not necessarily be rendered obsolete.

\section{RISK FACTORS}

In the management of any chronic or potentially chronic disease state, the primary care optometrist's principal job is to appropriately manage risk to prevent adverse outcomes. A small subset of $\mathrm{OH}$ patients will develop glaucoma, ultimately with the risk of visual impairment. A review of the available literature shows that the 15 -year risk estimates of unilateral blindness range from 3.1 to $10.5 \%$ in untreated $\mathrm{OH}$ patients and 0.9 to $8.6 \%$ in treated $\mathrm{OH}$ patients. ${ }^{56,57}$ Although these percentages seem low, their impact is severe. An understanding of the importance of various risk factors for progression and their application is pivotal to providing an informed consultation with the patient to reduce their risk of blindness. In the planning phase of OHTS, 20 baseline demographic and clinical factors were identified 
that might predict which patients would be more likely to develop glaucoma. Six years into the study, the relevant risk factors for conversion to glaucoma from $\mathrm{OH}$ were baseline age, vertical and horizontal cup-disc ratio, PSD, central corneal thickness (CCT) and intraocular pressure..$^{58}$ Interestingly, although multiple studies have shown an association between diabetes and the development and progression of glaucoma, OHTS initially found that diabetes conferred a protective effect against the development of POAG. ${ }^{58-63}$ The authors later acknowledged methodological issues that might account for this protective effect. With the use of more specific definitions for a present condition of diabetes, a history of diabetes was not significantly associated with protection against glaucoma. ${ }^{64}$ Additionally, although it has been suggested that the prevalence of POAG in African-Americans is 4-5 times higher than that in individuals of European descent, after adjusting for a thinner central corneal thickness and a larger cup-to-disc ratio at baseline in this demographic, race itself was not a statistically significant predictor of the development of glaucoma. ${ }^{58,65-68}$

The strongest and arguably most novel of the independent predictive risk factors noted above was CCT. Simply put, the risk of developing POAG is inversely correlated with the CCT. The study showed that average CCT was 553.1 \pm 38.8 $\mu \mathrm{m}$ among study participants who developed POAG and 574.3 $\pm 37.8 \mu \mathrm{m}$ among those who did not develop glaucoma. Subjects were further divided into three thickness subgroups: thin, intermediate and thick. The thin subgroup (average CCT of $530.8 \mu \mathrm{m}$ ) had a greater than three-fold higher risk of developing glaucoma than the thick subgroup (average CCT of $613.5 \mu \mathrm{m}){ }^{58}$ These findings mandate the use of CCT to evaluate risk in patients with ocular hypertension.

More recent studies on glaucoma have suggested that the relationship between the cornea and glaucoma involves more than just the anatomic thickness of that anterior tissue. ${ }^{69}$ It can be difficult to differentiate glaucomatous eyes from $\mathrm{OH}$ eyes on the basis of CCT alone, since there is a substantial overlap in thickness between the two groups. ${ }^{70}$ Although corneal hysteresis $(\mathrm{CH})$ was not included in the predictive risk factors assessed by OHTS, since it was not on the radar at the time, it has since emerged as an important risk factor for the development of, severity of, and rate of visual field loss in glaucoma. ${ }^{71-77}$ Corneal hysteresis is considered to be a measure of corneal viscous dampening, and thus directly assesses the cornea's resistance to deformation. ${ }^{78}$ It has been proposed that the characteristics of the corneal tissue itself, such as the ability to resist deformation, might reflect the constitution of the extracellular matrix (ECM). Since the cornea, sclera, peripapillary ring and lamina cribrosa are essentially constructed of that same ECM, it is plausible that their biomechanical characteristics might be similar. ${ }^{74}$ It has been proposed that an eye with more deformable anterior ocular tissues (cornea) might also be at higher risk for glaucomatous damage secondary to the ef-

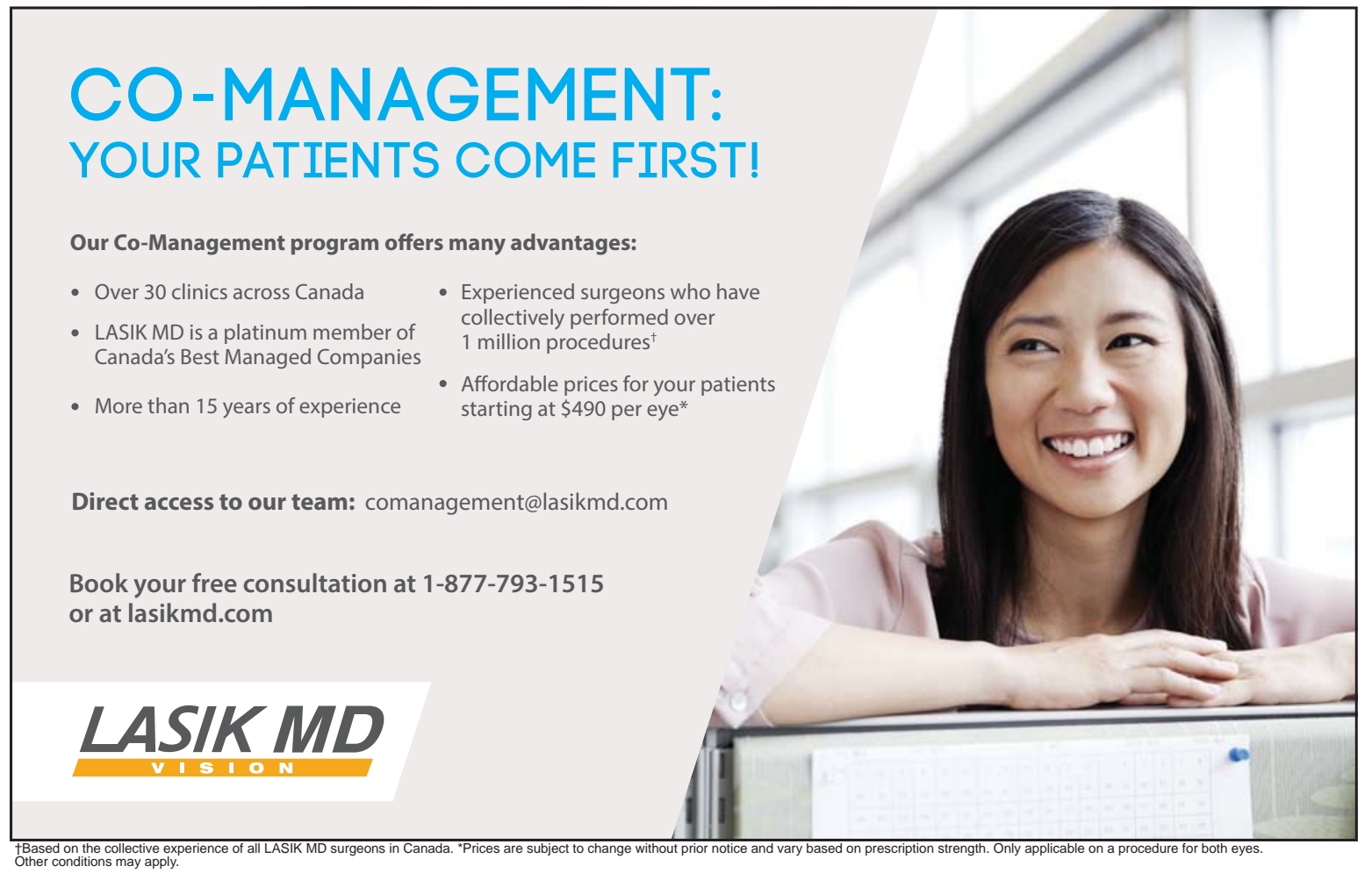

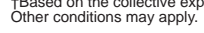


fect of IOP on posterior ocular tissues. ${ }^{79}$ It has additionally been demonstrated that eyes with lower $\mathrm{CH}$ seem to be associated with altered optic nerve head compliance during the adjustment of IOP. ${ }^{79}$ Multiple studies have demonstrated that patients with various forms of glaucoma have significantly lower corneal hysteresis values than normals. ${ }^{71,72,80-86}$ Sullivan-Mee and co-workers ${ }^{70}$ assessed $\mathrm{CH}, \mathrm{CCT}$ and IOP in patients with $\mathrm{OH}$ and POAG and found that only $\mathrm{CH}$ was independently associated with POAG and $\mathrm{CH}$ was the only variable that differentiated $\mathrm{OH}$ from POAG, with significantly lower $\mathrm{CH}$ in the POAG group. Consequently, the measurement of corneal hysteresis in $\mathrm{OH}$ patients can provide additional information that can help the optometrist when assessing the risk of conversion.

The presence of optic disc hemorrhage (DH) is widely accepted as one of the strongest risk factors for the development and progression of glaucoma ${ }^{87,88} \mathrm{DH}$ is rarely found in normal eyes and its prevalence in $\mathrm{OH}$ patients has been reported to range from $0.04 \%$ to $10 \% .{ }^{89}$ Although patients with $\mathrm{DH}$ at baseline were excluded from participation in OHTS, the investigators did monitor their presence over an average follow-up of 96.3 months. They sought to compare the rate of $\mathrm{DH}$ detection by clinical examination and photographic review, to assess the incidence of and predictive factors for $\mathrm{DH}$ in annual disc photos, and to determine whether $\mathrm{DH}$ predicted the development of POAG in the OHTS participants..$^{90}$ They found that only $16 \%$ of DH were detected by clinical examination, and $84 \%$ were detected by photographic review. The discrepancy between clinical and photographic detection in this study has not been noted in other studies. ${ }^{91,92}$ The baseline risk factors in participants with DH were similar to those in participants who developed glaucoma: older age, increased cup-to-disc ratio, and thinner CCT. Patients with DH were six times more likely to develop glaucoma than those without DH. The cumulative incidence of POAG in eyes with DH was $13.6 \%$, compared to $5.2 \%$ in eyes without $\mathrm{DH}$, suggesting that $\mathrm{DH}$ are additional predictive risk factors for the development of POAG. However, the authors cautioned that, since $86.7 \%$ of the participants with DH did not reach a glaucomatous end point by the end of follow-up, it could not be concluded that disc hemorrhages are synonymous with glaucoma. Furthermore, they suggested that the initial results do not direct practitioners to treat all patients with $\mathrm{OH}$ who have $\mathrm{DH} .{ }^{90}$ In a $\geq 5$ year follow-up study, the OHTS group compared the rate of visual field change in eyes with and without DH: the rate of visual field deterioration in eyes with $\mathrm{DH}$ was more than twice that in eyes without DH. Randomization to the treatment group decreased the likelihood of developing DH, implying that treatment may provide a protective effect against $\mathrm{DH}$. The authors concluded that the presence of DH should alert the managing clinician to a heightened risk that may require more aggressive intervention to prevent a negative clinical outcome. ${ }^{93}$ Given the negative prognostic importance of $\mathrm{DH}$, to accurately assess the risk and appropriately intervene, it is critical that the clinician look for the sometimes subtle presence of DH using a combined approach of concentrated clinical examination and stereoscopic disc photography. ${ }^{87,88}$

RISK ASSESSMENT/ RISK CALCULATORS

Since OHTS demonstrated that treatment was efficacious, it might seem reasonable to conclude that treating all patients with $\mathrm{OH}$ is an appropriate preventative measure that hedges against glaucoma. However, after an exhaustive analysis, the OHTS investigators concluded that the treatment of all ocular hypertensive individuals is neither medically indicated nor economically justifiable due to the high prevalence of the condition, the low conversion rate to POAG and the cost, inconvenience, and possible adverse effects of treatment. ${ }^{14}$ The important point is that the OHTS identified that a substantial susceptible minority of patients can benefit from medical intervention and identification of these individuals is critical. Specifically, the 5-year risk of converting to glaucoma was 36\% in the highest-risk subgroup (>13\% estimated 5-year risk of glaucoma) and predicted to be $42 \%$ at 10 years in that subgroup. ${ }^{35,58}$ In comparison, the lowest-risk subgroup ( $<6 \%$ estimated 5-year risk of glaucoma) had a 5 -year risk of conversion of $2 \%$ and a predicted $7 \%$ risk at 10 years. ${ }^{35,58}$

Although knowledge of the factors that can predict the development of glaucoma is crucial, integrating this knowledge into the care of an individual $\mathrm{OH}$ patient is far from a simple, streamlined process. To help streamline this process and provide a consistent template with which to make evidence-based decisions, multiple prediction models have been developed. ${ }^{94-96}$ For these models to be confidently accepted by practitioners, there must be some conclusive evidence to support their utility. Prediction models are developed from study populations and as a result cannot always be generalized beyond that specific population. It is widely accepted that a prediction model should not be applied in clinical practice before it has been validated in at least one other population and preferably by different investigators. ${ }^{97}$ The most prominent validated risk prediction model available relies on pooled data from the observation group of the Ocular Hypertension Treatment Study and the placebo group of the European Glaucoma Prevention Study (EGPS). ${ }^{98}$ EGPS, much like OHTS, sought to evaluate the efficacy of reducing IOP to prevent or delay the development of POAG in patients affected by OH. EGPS was a multicenter randomized, double-blinded, placebo-controlled clinical trial involving 1,077 Caucasian subjects between 30 and 
80 years of age with open angles, an IOP of at least $22 \mathrm{mmHg}$ but not higher than $29 \mathrm{mmHg}$ in one eye, and two normal and reliable visual fields. ${ }^{99}$ EGPS identified multiple predictive factors for the development of glaucoma that were highly consistent with OHTS, including older baseline age, larger vertical C/D ratio, higher PSD, and thinner CCT. ${ }^{100}$ Based on these consistencies, as well as other key similarities in their respective definitions and protocols, the OHTS and EGPS groups were able to collaboratively pool and analyze their data. This resulted in a more statistically sound risk-prediction model based on a larger number of participants and a larger number of POAG end points.$^{97}$ From this prediction model the collaborating groups developed a risk calculator that could be useful in the clinic to assess an individual's 5-year risk of conversion to POAG. There are two OHTS-EGPS based systems available for users of the calculator: one using a Cox proportional hazards model and one using a point system. ${ }^{97}$ These calculators may be accessed at http://ohts.wustl.edu/risk/calculator.html. Case examples are presented to demonstrate their appropriate use. The caveat is that these calculators will be most useful in patients with clinical characteristics similar to those of the patients enrolled in these studies.

Although the 5-year risk of converting to glaucoma from $\mathrm{OH}$ is a highly interesting piece of information, most optometrists may not find this percentage particularly meaningful in their treatment decisions. Instead, the answers to more clinically relevant questions, such as; "Given what you see today, at what IOP would you have recommended IOP lowering?" and "If the patient were to come back in 6 or 12 months, all other things unchanged, how much higher would the IOP have to be for you to initiate treatment?" might be more meaningful for most practitioners. Jampel and Boland ${ }^{101}$ asked these exact questions and sought to provide evidence-based answers. Using data from the combined OHTS/EGPS analysis they developed a 5-year risk calculator, known as the "threshold to treat" calculator, that produces an IOP, rather than percentage risk, at which treatment should be strongly considered.101 This calculator may be accessed at http://oil.wilmer.jhu.edu/threshold. Since IOP is easily and often assessed, and the only clinically modifiable risk factor in glaucoma management, this calculator repackages the data to provide information that is more commonly used and likely more relevant in practice. The threshold to treat calculator is clearly impactful, but has the same shortcomings as the OHTS/EGPS risk calculator: it captures only the static IOP acquired by tonometry at the time of recording, and fails to consider the dynamic nature of IOP, which is rarely completely assessed in the clinical setting. ${ }^{101}$

CONFOUNDING FACTORS/CAPTURING IOP

Intraocular pressure is a dynamic process, the variation of which may confound risk assessment in patients with ocular hypertension. It is well known that IOP varies spontaneously over a $24 \mathrm{hr}$ period. ${ }^{102}$ Therefore, measurement in an office setting results in an incomplete picture. Although serial tonometry during office hours may better capture diurnal variation, peak IOP has been reported to occur outside of normal office hours in most patients. ${ }^{103,104}$ In fact, Jonas et al. ${ }^{105}$ showed that any single IOP measurement acquired between 7:00 am and 9:00 pm had a $75 \%$ probability of missing the peak of the $24 \mathrm{hr}$ IOP curve. Accordingly, IOP data gathered over a 24 -hr period provides the most complete assessment of an individual's risk characteristics. Grippo et al. ${ }^{106}$ compared the 24-hr IOP patterns of healthy patients to those of patients with untreated OH and early signs of POAG. After the investigators established baseline 24 -hr IOP curves, patients were monitored over $4.3 \pm 3.8$ years for glaucoma development. Diurnal and nocturnal curves were compared among the groups. Patients from the untreated $\mathrm{OH}$ group who converted to glaucoma manifested similar baseline 24-hr IOP curves as those in the initial glaucoma group, and were dissimilar to both the healthy controls and non-converters. Specifically, both the converters and initial glaucoma group exhibited higher diurnal mean IOPs as well as greater diurnal IOP variation compared to healthy controls. Although continuous IOP-measuring devices are on the horizon, they are not yet practically usable. ${ }^{107}$ This study shows that acquiring multiple IOP readings at different times of day in an office may provide adequate risk assessment, without capturing the true variability in 24-hr IOP.

Diurnal assessment does not, however, account for the long-term variability of IOP measured at multiple examinations over time. Bhorade et al. ${ }^{108}$ analyzed IOP data from the OHTS with the goal of describing the variability of IOP measurements within the same eye and between the right and left eyes over a 60 -month period. ${ }^{108}$ They found that $13 \%$ of eyes had a difference in IOP of $>20 \%$ between two consecutive visits. The mean absolute difference in IOP measured within the same eye between all consecutive visits was within $3 \mathrm{mmHg}$ in $66 \%$, between 3 and $5 \mathrm{mmHg}$ in $24 \%$, and $>5 \mathrm{mmHg}$ in $10 \%$. Although the authors noted that the strict study protocols likely minimized the variability typically seen in clinical practice, the findings additionally highlight the complexity of obtaining consistent IOP data from which to adequately assess risk in ocular hypertensives. 
Independent of the physiological properties of IOP, over-detection secondary to systematic errors in tonometry may lead to unnecessary treatment, resulting in an undue burden of treatment on the patient. Conversely, underdetection and treatment may have dire consequences with respect to vision. In clinical practice, measurement of IOP is compulsory and used to screen for high-risk characteristics and monitor variations in the disease state, as well as to evaluate the efficacy and effectiveness of treatment. Most practices use Goldmann applanation tonometry to achieve these purposes. Both Goldmann applanation and non-contact tonometers are known to produce clinically significant systematic errors if inadequately maintained and calibrated. ${ }^{109-113}$ An analysis of IOP data from 3,654 participants in the Blue Mountains Eye Study revealed that a tonometer that consistently under- or over-reads by 1 mmHg will miss $34 \%$ of individuals with $\mathrm{OH}$ or yield $58 \%$ more positive screening tests, respectively. ${ }^{114} \mathrm{This}$ study underscored the need to maximize the repeatability of measurements through calibration.

In the actual management of glaucoma or ocular hypertension, the aforementioned historical assumption that day-to-day IOP variation is repeatable at any given time has led to the widespread practice of quarterly "pressure checks", performed at similar times of day, to help the practitioner gauge the efficacy and effectiveness of their prescribed treatment. ${ }^{115}$ Any difference in IOP from baseline is then attributed to the effect of medication or patient non-adherence. Multiple studies have shown that diurnal IOPs and the measurement of these IOPs are not repeatable in the short term in treated glaucomatous individuals. ${ }^{116-120}$ Rotchford et al. ${ }^{115}$ examined the justification for determining the effectiveness of medication using the traditional time-of-day standardized approach in treated patients with ocular hypertension. The variation of repeated IOP measurements in treated $\mathrm{OH}$ patients at the same time on different days lies within a range between $\pm 21.2 \%$ and $\pm 23.1 \%$ from baseline. The authors concluded that, even under ideal conditions, a day-to-day variability of $\pm 20 \%$ significantly undermines both the precision of IOP measurement and the estimation of medication effectiveness even when the time of day is standardized. ${ }^{115}$ These studies suggest that optometrists should obtain multiple IOP readings prior to assessing the success or failure of therapy in $\mathrm{OH}$ patients they elect to treat. A clinical assumption that an ineffective treatment is effective and conversely that an effective treatment is ineffective carries multiple risks and only increases the potential burden on the patient, which can avoided by the careful practitioner.

VALUE OF A RISK CALCULATOR IN PRACTICE

Although the OHTS-EGPS risk calculator has been shown to be accurate in multiple populations, the application and influence of this calculator in routine practice can be debated and may even meet with resistance by some physicians. A study conducted by Mansberger and Cioffi ${ }^{121}$ compared the ability of ophthalmologists to estimate an individual's risk of converting to glaucoma to the results of a risk calculator. They showed that there was a high range of probability estimates among practitioners, which could potentially lead to under- and over-treatment and underscores the need for a tool that would give consistent results.

Boland et al. ${ }^{122}$ studied whether physician subspecialty training, access to a formal risk calculator or patient age influenced physician treatment recommendations in cases of OH. Using the results from OHTS, the authors generated 50 simulated case scenarios. These scenarios used the 5 risk factors identified by OHTS found in the risk calculator, in addition to the patient's diabetic status. One hundred eighteen members of the American Academy of Ophthalmology and 58 members of the American Glaucoma Society participated in this study by reviewing these cases with and without an estimated risk of conversion. The authors determined that inclusion of the risk calculator significantly increased physician confidence and reduced inconsistency in the decision-making process. Specifically, addition of the risk calculator decreased the threshold to treat from a $22 \%$ risk of conversion over 5 years to $17 \%$ in glaucoma subspecialists, and from $16 \%$ to $13 \%$ in a non-glaucoma-trained group. ${ }^{122}$ They concluded that, at least in simulated cases, the participating physicians underestimated the risk of developing glaucoma. This study supports the potential of the risk calculator to provide more confident and accurate management, which would hopefully reduce the functional consequences of under-treatment.

Practically, if the risk calculator is to be a truly useful decision-support tool, it would need to have significant intervisit repeatability, in a non-study, real-world clinical setting. Song et al. ${ }^{123}$ investigated the longitudinal variability of the risk calculator in a glaucoma referral practice. They reviewed the charts of 27 untreated $\mathrm{OH}$ patients for a mean of $98.3 \pm 18.5$ months. Using the OHTS/EGPS risk calculator to calculate glaucoma risk for each patient at each follow-up visit, they determined that the 5-year estimated risk of conversion to POAG among untreated patients varied substantially (up to 10-fold) during follow-up. Specifically, the baseline risk of conversion was $14.0 \pm 12.0 \%$ (range 2.9 to $49.2 \%$ ) in the non-POAG group, and $22.5 \pm 11.5 \%$ (range 14 to $52.3 \%$ ) in the group that developed POAG. ${ }^{123}$ The results of this study highlight the danger in making decisions based on a single risk calculation. In daily practice, data 
points can exhibit substantial fluctuations, most notably for IOP, for which complete diurnal and nocturnal curves are not routinely obtained. The authors concluded that "ultimately, the availability of and access to a risk calculator does not guarantee widespread adoption by clinicians, nor does the data derived from that calculator, although compelling in spite of variability, mandate its use at this juncture". ${ }^{123}$

\section{EFFECTIVENESS OF TREATMENT}

When interpreting the results of any randomized clinical trial, it is important to determine whether a statistically significant result is also clinically significant. Clinical significance refers to the size of a treatment effect at which a clinician feels adoption of a treatment modality would be justified in clinical practice. ${ }^{124}$ The "number-needed-to-treat" (NNT) has been used to apply valid, statistically significant results to the care of individual patients. Since we cannot precisely know which patients will benefit from treatment, the NNT gives an estimate of how many individuals will need treatment before any one patient will realize a benefit. ${ }^{125}$ NNT is derived by calculating the inverse of the absolute risk reduction. ${ }^{126}$ An ideal NNT is 1; treatment of 1 patient prevents 1 harmful outcome. Although NNT has been used to apply the results of RCTs to individuals, it is a statistical construct based on averages from these RCTs. ${ }^{57}$ The caveat is that these NNTs are not perfectly applicable to individuals who do not resemble patients from the RCTs. Nonetheless, NNT provides some understanding and general guidance that is not otherwise apparent in assessing the value of prophylactic treatment in patients with $\mathrm{OH}$. In fact, when clinicians and policymakers have been presented with research results in different formats, they made more conservative decisions when they received treatment effects expressed as NNTs than when they received them as relative or absolute risk reductions. ${ }^{127}$

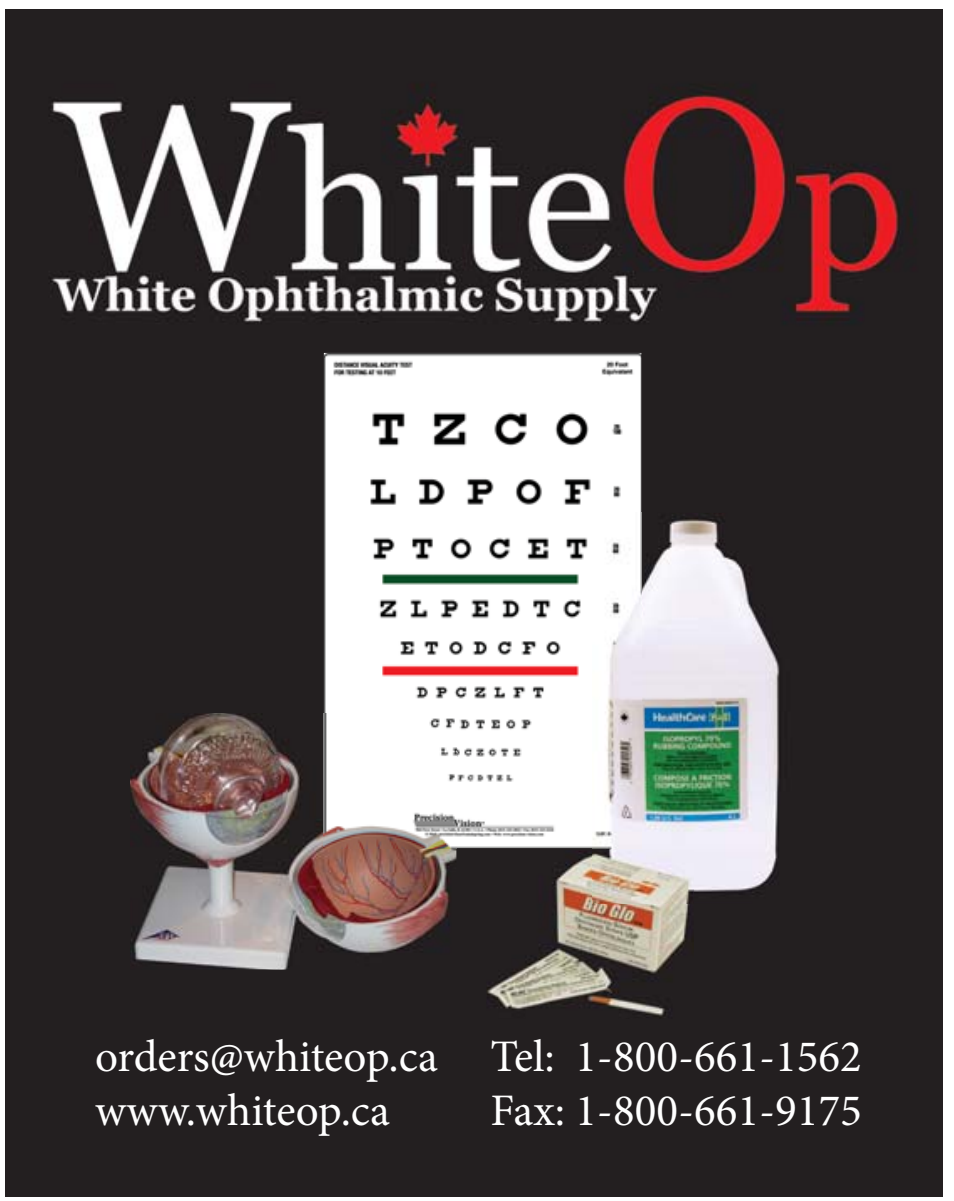


An example of a NNT comes from the field of cardiology. In a meta-analysis of 10 RCTs (70,388 total subjects) that explored the benefit of statin use in people without established cardiovascular disease but with cardiovascular risk factors, Brugts et al. ${ }^{128}$ assessed all-cause mortality and major coronary and cerebrovascular events, and found that the respective NNTs were 167, 77, and 250, respectively. In this example, 250 patients would require treatment to prevent one major cerebrovascular event. Further, if the treating doctor considers that this low potential of success outweighs the burden of treatment, then they accept the fact that they will be unable to predict which of those 250 patients will benefit from, be harmed by, and be unaffected by the treatment. It is important to note that, although a NNT of 250 seems prohibitively high relative to an ideal of 1 , it is inappropriate to compare NNTs across disease states of varying severities. NNT is a function of the severity of the disease, the intervention undertaken, and the likely outcome. ${ }^{127}$

This clinical conundrum of who to treat is no different in the case of ocular hypertension, although the NNTs may be more or less acceptable depending on how the clinician views the severity of the potential outcome. The 10 -year estimated incidence of POAG was reduced by approximately $50 \%$ in all three OHTS risk subgroups, consistent with the relative risk reduction found at the 5 -year point of the study. ${ }^{35}$ The absolute risk reduction in each subgroup may be a more useful statistic than measuring the relative risk reduction, which can be misleading in that individuals with substantially different absolute risks may have the same relative risk percentage. The absolute risk reduction is the difference in the rate of an outcome, POAG in this case, in the control group minus that rate in the treatment group. ${ }^{124}$ In the lowest-risk subgroup $7 \%$ of the observation group and $4 \%$ of the treatment group developed POAG, an approximate $50 \%$ risk reduction, but a minimally convincing absolute risk reduction of just 3\% over 10 years..$^{35}$ Expressed in NNT, 33 (1 divided by 0.03 ) patients would need to use daily eye drops for 10 years to prevent one patient from developing POAG as defined by the OHTS criterion. In the highest-risk subgroup, at 10 years, $42 \%$ and $19 \%$ of the cases in the observation and treatment groups, respectively, developed POAG, for an ARR of $23 \%$ and a NNT of approximately 4 (1 divided by 0.23 ). It can be asserted that treating 4 patients with daily medications over 10 years to prevent a case of glaucoma is more impactful than treating 33 to achieve the same result. The NNTs found in the 13-year review of the low-, moderate- and high-risk subgroups from phase II were 98, 16, and 7, respectively, which constitutes additional evidence that the benefit of treatment is most evident in the group with higher baseline risk. ${ }^{15}$ In summary, NNT can be a valuable part of decision-making. Unfortunately, it fails to predict which of the treated patients will benefit from treatment. Like all research results, NNT should not be used in isolation, but rather should be integrated with patient preferences, caregiver experience and judgement, and local constraints and conditions. ${ }^{127}$

When considering a treatment's efficacy, it is also critical to assess the significance of the treatment's adverse effects. This provides a comprehensive assessment of the risk/benefit ratio in treatment. Treatment safety was monitored throughout OHTS, and there was no evidence of excess risk in the medication group for reported symptoms, overall number of new medical conditions, worsening of preexisting conditions, hospitalizations, or mortality. ${ }^{33}$ The authors suggested that these safety findings support the notion that the treatment protocol in that study was successful. This favorable benefit profile, although not perfectly applicable outside of that study, should further allay concerns about treatment.

The use of healthcare resources is, by economic measures, not worthwhile unless there is a corresponding benefit. Evaluating the economic value of a treatment is an additional way to assess a treatment's effectiveness. The OHTS group analyzed the cost-utility of treatment on a hypothetical cohort of people with an IOP $\geq 24 \mathrm{mmHg}$. Four treatment thresholds were considered: (1) treat no one; (2) treat those with a $\geq 5 \%$ annual risk of developing glaucoma (approximately 10\% of the subjects in OHTS); (3) treat people with a $\geq 2 \%$ annual risk of developing POAG (approximately 30\% of the subjects in OHTS) and (4) treat everyone. The value of treatment was based on how that intervention impacted the patient's quality of life, expressed in quality adjusted life-years (QALY). ${ }^{14}$ Treatment is considered to be cost-effective if the value placed by society on the QALY exceeds the cost that society would expend to acquire that QALY. ${ }^{129}$ The authors concluded that the treatment of patients with an IOP of $\geq 24 \mathrm{mmHg}$ and $\mathrm{a} \geq 2 \%$ annual risk of developing glaucoma is likely to be cost-effective. ${ }^{14}$ This is equivalent to a $\geq 10 \%$ risk of developing glaucoma in the 5 -year risk period used in OHTS. This signifies that it would be cost-effective to treat approximately $30 \%$ of patients resembling the study group from OHTS. For an additional perspective on this $\geq 2 \%$ annual risk threshold, Boland et al. ${ }^{130}$ assessed the threshold to treatment tolerance of glaucoma specialists, and found an average tolerance of a $4.6 \%$ annual risk of developing glaucoma without and a $3.4 \%$ annual risk with a risk calculator. This indicates that subspecialists are willing to treat approximately $10 \%$ of patients involved in OHTS. Therefore, a $2 \% /$ year threshold to treat could be considered fairly liberal, relative 
to subspecialist clinicians, and still be cost-effective. Kymes et al. ${ }^{131}$ also later evaluated the influence of a patient's life expectancy on the cost-effectiveness of preventative treatment. They concluded that, assuming a willingness to treat approximately $30 \%$ of OHTS participants, an $\mathrm{OH}$ patient would need to live at least an additional 18 years to make treatment cost-effective to society. In higher-risk categories, the required life expectancy would be reduced to 7 to 10 years. ${ }^{131}$ Although cost-effectiveness is, undoubtedly, a less personal model of the effectiveness of treatment, it still provides an additional perspective.

\section{TREATMENT}

As previously mentioned, the treatment goal in OHTS, was to achieve a minimum $20 \%$ reduction from the average of the qualifying IOP and the IOP at the baseline randomization visit. ${ }^{28}$ The $20 \%$ target IOP was considered to reflect current clinic practice at the time and is still considered a reasonable initial target in managing $\mathrm{OH}$ patients who are at a moderate risk of conversion. ${ }^{34,132-136}$ When OHTS was initiated, $94 \%$ of participants were prescribed topical -adrenergic antagonists (-blockers) in an attempt to meet that target. ${ }^{137}$ Notably, none of the patients initially used prostaglandin analogues (PGAs) due to their lack of availability at the start of the study. However, at the end of phase I, close to $50 \%$ of patients were prescribed PGAs ${ }^{34}$. Mono-therapy with any agent was not always sufficient to achieve the target IOP reduction. In phase I, 2 or more topical medications were prescribed for $39.7 \%$ of participants, and 3 or more medications were prescribed for $9.3 \%$ of participants. ${ }^{34}$ In an OHTS comparison of the IOP response to blockers and PGAs, PGAs reduced IOP by an average of $2.1 \mathrm{mmHg}$ and $1.3 \mathrm{mmHg}$ more than blockers in African-American and Caucasian patients, respectively. ${ }^{137}$ Medeiros et al. ${ }^{138}$ reported that each 1-mm $\mathrm{Hg}$-higher average follow-up IOP increased the risk of conversion from $\mathrm{OH}$ to glaucoma by $20 \%$. This emphasizes the need to use the most efficacious medication in these cases. Therefore, PGAs are the initial medication of choice in the goal of at least a $20 \%$ or greater IOP reduction in treated $\mathrm{OH}$ patients.

Although selective laser trabeculoplasty (SLT) is not widely employed in optometric care, it is an additional firstline therapeutic option. A meta-analysis on the efficacy of SLT with open angle glaucoma showed that SLT is not inferior to medication for reducing IOP and achieving treatment success. ${ }^{139} \mathrm{In}$ high-risk OH patients, Shazly et al. ${ }^{140}$ demonstrated that SLT can be particularly beneficial in those with CCT of $<555 \mu \mathrm{m}$, with an effective duration of at least 30 months post-treatment. Several studies have also concluded that SLT may offer cost advantages over medical therapy. Lee and Hutnik ${ }^{141}$ compared the projected 6-year cost of SLT to topical medications in the Ontario Health Insurance Plan (OHIP) for patients with open-angle glaucoma aged 65 and older. Based on the assumption that bilateral 180-degree SLT was repeated 3 years from the initial treatment, SLT resulted in a savings of $\$ 580.53, \$ 2,042.82$ and $\$ 3,366.65$ per patient over mono-, bi- and tri-drug therapy, respectively, over that same 6 years. ${ }^{141}$ Seider et al. ${ }^{142}$ showed similar findings in that SLT was less expensive than most brand-name medications within 1 year and less expensive than generic latanoprost and generic timolol after 13 and 40 months, respectively. Stein et al. ${ }^{143}$ determined that both PGAs and laser trabeculoplasty are cost-effective options for the management of newly diagnosed mild open angle glaucoma compared to observation. Based on the assumption that patient adherence to topical medication is not $100 \%$, they estimated that, at current PGA prices, laser trabeculoplasty may be a more cost-effective alternative than PGAs. Ultimately, the selection of a specific topical hypotensive medication or use of SLT will be determined by the individual patient's systemic and ocular health status, risk tolerance and insurance factors.

\section{CONCLUSIONS}

The management of Ocular Hypertension is an ongoing challenge for the primary eye-care practitioner, and is complicated by an uncertain disease course and evidence-based research showing that the vast majority of patients will not develop POAG. The evidence clearly supports the treatment of patients with high-risk characteristics and treatment of approximately $1 / 3$ of patients can be economically justifiable. Age, health status, life expectancy, burden of treatment, quality of life, patient and practitioner risk tolerance and attitudes toward disease and treatment all add to the complexity of the decision-making process. The decision to treat is serious, since it potentially sentences the patient to life-long treatment without a guarantee of benefit from that treatment. Decision-support tools such as the OHTS/ EGPS risk calculator and "threshold to treat" calculator reduce uncertainty and provide direction that was previously unavailable. However, they are limited by variations in IOP and the ability to observe those variations. A patient-centered approach is necessary in cases where the absolute need to treat can be disputed. In concert with evidence-based risk assessment, this approach can effectively guide the optometrist and informed patient in enacting customized management that is appropriate for the individual. 
"Clinicians should make certain that their patients have a clear understanding regarding the risk of disease progression and its potential impact on their quality of life in advising them concerning treatment options. Those patients who are more risk averse are more likely to view treatment as beneficial, although those patients with greater tolerance for risk of progression and an aversion to medication may perceive less benefit." - The Ocular Hypertension Treatment Study Group

\section{Illustrative Case}

This case is a typical example of $\mathrm{OH}$ encountered in our practice and reflects the complexity of management decisions in these patients. Our patient was a 70-year-old Caucasian male with a stable history of prostate cancer post-radiation and hormone therapy x 5 years, post-amputation secondary to peripheral vascular disease (currently on warfarin), and well-controlled hypertension and hyperlipidemia. His intraocular pressures ranged from 23-33 $\mathrm{mmHg}$ OD, OS, and the average of 8 IOP readings over the last 3 years was $28 \mathrm{mmHg}$. CCTs were 599 and $597 \mu \mathrm{m}$, respectively. Corneal hysteresis values were $10.5 \mathrm{mmHg}$ and $10.7 \mathrm{mmHg}$, which are average for a Caucasian and confer no additional risk. Optic nerves (Fig. 1) were judged by multiple examiners to be .25 OD/OS and cp-RNFL measurements were unremarkable (Fig. 2). Visual fields (Fig. 3) showed mild "reverse cataract" patterns in each eye due to patient over-performance on this initial field. MDs were both positive and there were no glaucomatous defects. With the OHTS/EGPS risk calculators found at http://ohts.wustl.edu/risk/calculator.html, the point system generates a 5-year estimated risk of POAG of $10 \%$ and $3.5 \%$ with the continuous method, using an average of $28 \mathrm{mmHG}$. These percentages would fall in the moderate- and low-risk subcategories of OHTS, respectively. With the "Threshold to Treat" calculator at http://oil.wilmer.jhu.edu/threshold/, and with an estimated threshold for a 5 -year risk of progression of $13 \%$ (based arbitrarily on the lowest percentage in the highest-risk subcategory), the IOP threshold to initiate treatment exceeds $32 \mathrm{mmHg}$. After we educated the patient on his risk of developing glaucoma, the risk of functional loss from glaucoma, and what treatment would entail, we and the patient mutually decided to continue monitoring. This case perfectly illustrates the need to comprehensively assess the risk in $\mathrm{OH}$ beyond IOP, the critical role of CCT in increasing or decreasing that risk, and the burden of treatment relative to the likely benefit of treatment. In this case, the mutual decision to delay treatment was multifactorial and included the patient's poor health status, current burden of systemic medical therapy, age and limited life expectancy, risk assessment and the risk tolerance of both parties. A different patient with the same risk factors and different attitudes toward risk and treatment may desire treatment, which reinforces the notion that there is no one-size-fits-all approach to these patients.

Figure 1: ONH Photos

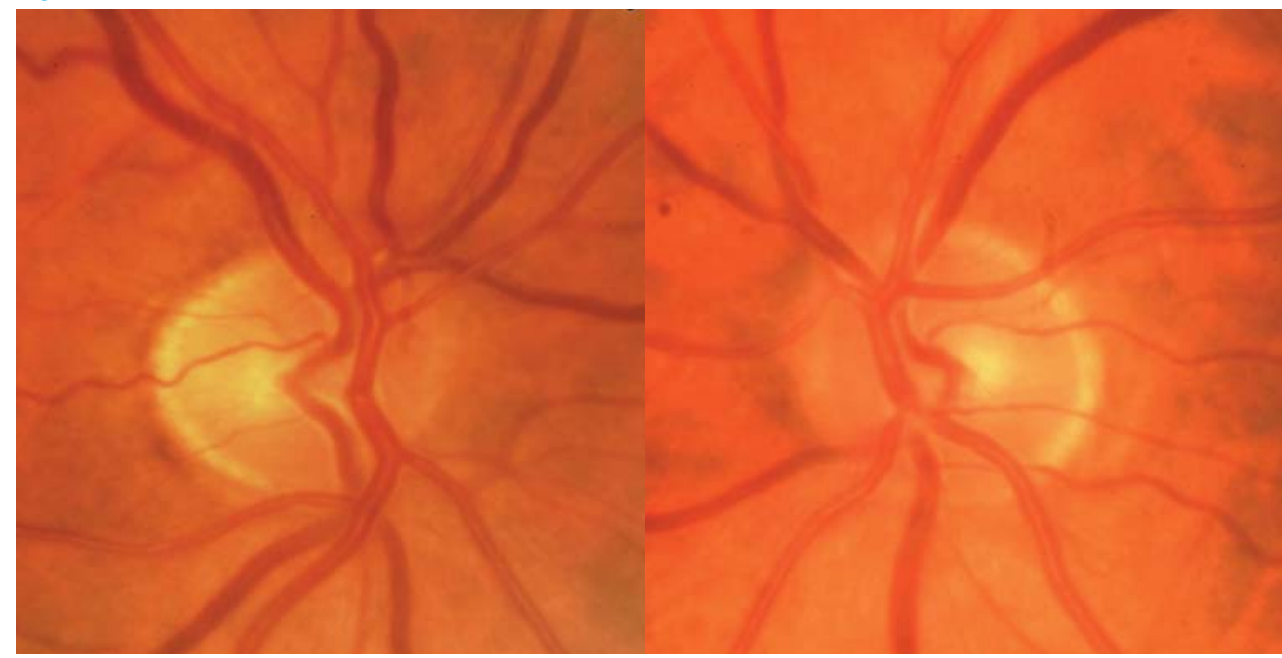


Figure 2: $C p-R N F L$

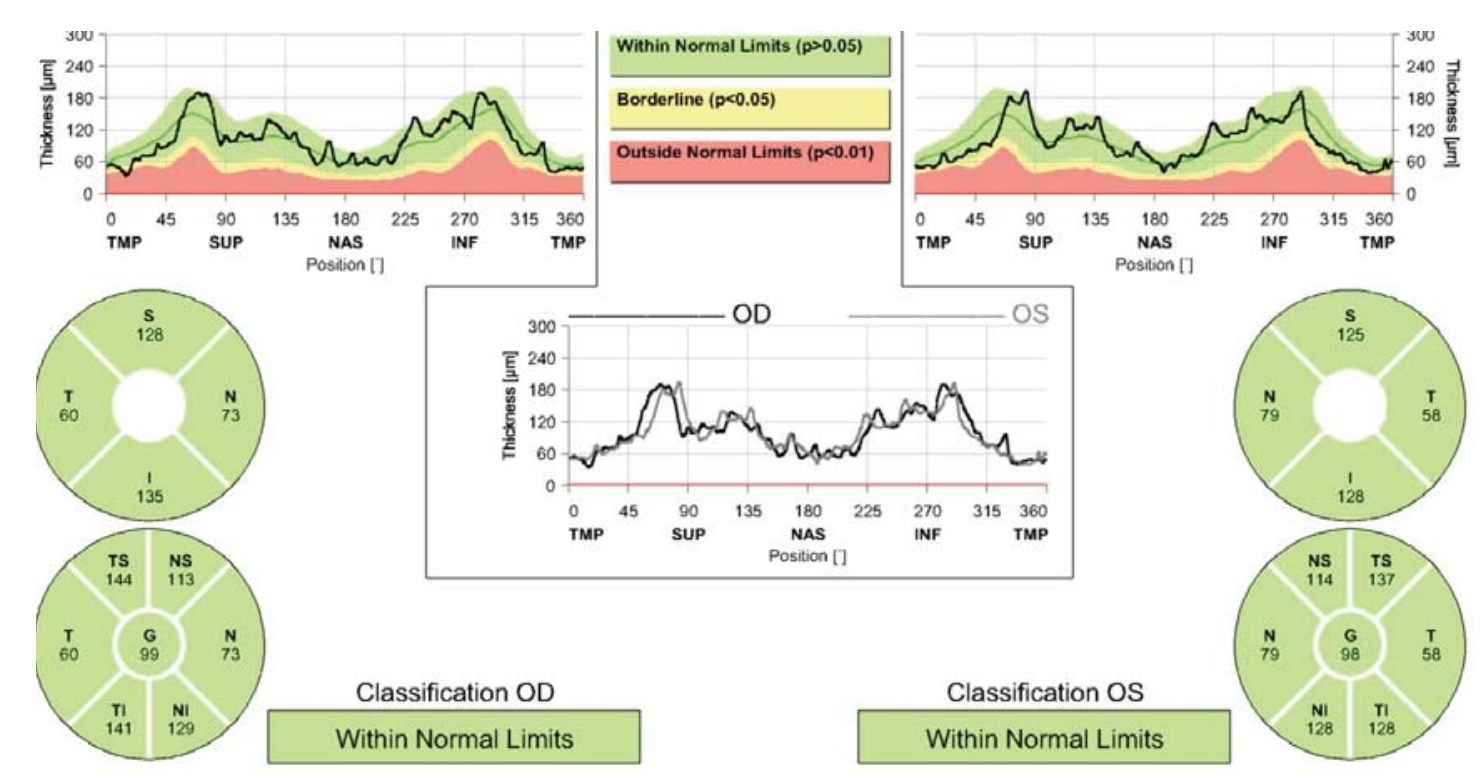

Cp-RNFL scan has good quality scores with good segmentation and good reflectivity. Inter-eye and intra eye symmetry is excellent and retinal thickness is well within normals per the normative database. No apparent pathology exists.

Figure 3: Visual Fields

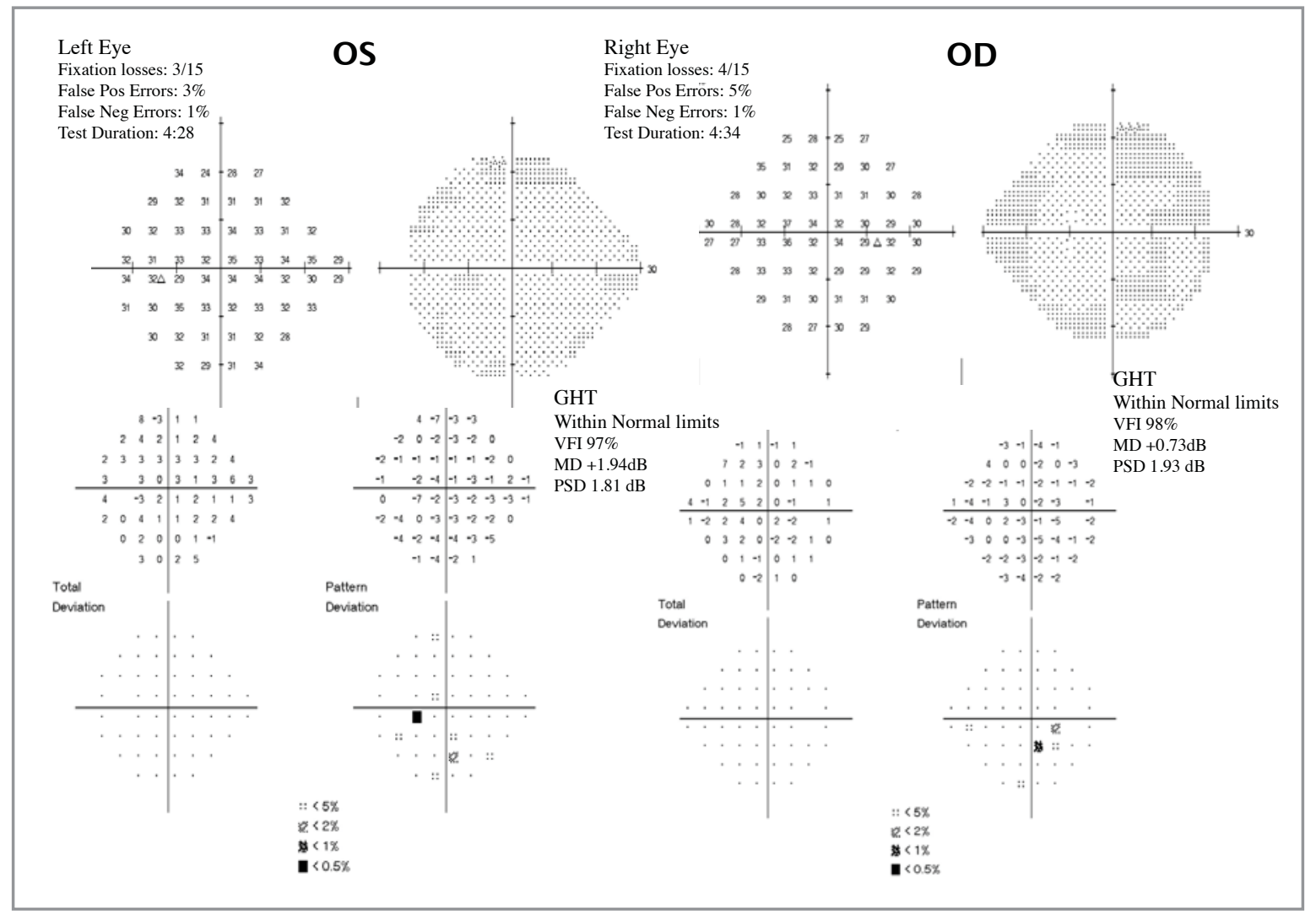




\section{REFERENCES}

1. Tham YC, Li X, Wong TY, et al. Global prevalence of glaucoma and projections of glaucoma burden through 2040: A systematic review and meta-analysis. Ophthalmology 2014; 121:2081-90.

2. Buys YM, Gaspo R, Kwok K. Referral source, symptoms, and severity at diagnosis of ocular hypertension or open-angle glaucoma in various practices. Can J Ophthalmol 2012; 47:217-22.

3. You YX, Chen CX, Ma K, et al. Ocular hypertension. Acta Ophthalmol 2013 Nov; 91(7):e587-9.

4. Linner E, Stromberg U. The course of untreated ocular hypertension: A tonographic study. Acta Ophthalmol 1964; 42: 836-48.

5. Prum BE, Lim MC, Mansberger SL, et al. Primary Open-Angle Glaucoma Suspect. American Academy of Ophthalmology Preferred Practice Patterns 2010; 1-32.https://www.aao.org/preferred-practice-pattern/primary-open-angle-glaucoma-suspect-ppp-2015. Last accessed 7/27/2015

6. Boey PY, Mansberger SL. Ocular hypertension: An approach to assessment and management. Can J Ophthalmol 2014 Dec; 49(6):489-96.

7. Armaly MF. On the distribution of applanation pressure. I. Statistical features and the effect of age, sex, and family history of glaucoma. Arch Ophthalmol 1965 Jan; 73:11-8.

8. Leydhecker W, Akiyama K, Neumann HG. Intraocular pressure in normal human eyes. Klin Monbl Augenheilkd Augenarzrl Fortbild 1958; 133(5): 662-70.

9. Leydhecker W. Tonography in the early diagnosis of simple glaucoma: A critical review on its fundamental conceptions and presentation of a new method. Trans Ophthalmol Soc UK 1958; 78: 553-64.

10. Leydhecker W. On the distribution of glaucoma simplex in apparently healthy population not treated by ophthalmologists. Doc Ophthalmol 1959; 13:359-88.

11. Bertelsen T, Davanger M, Kolstad A, et al. Measurement of intraocular pressure (Schiotz) and slit-lamp examination of the personnel of a large business organization. Tidsskr Nor Laegeforen 1965 Mar 1;85:449-53.

12. Davanger M, Holter O. The statistical distribution of intraocular pressure in the population. Acta Ophthalmol 1965;43:314-22.

13. Van Gestel A, Webers CA, Beckers HJ, et al. Ocular hypertension and the risk of blindness. J Glaucoma 2015 Jan; 24(1):9-11.

14. Kymes SM, Kass MA, Anderson DR, et al. Management of ocular hypertension: A cost-effectiveness approach from the Ocular Hypertension Treatment Study. Am J Ophthalmol 2006 Jun; 141(6):997-1008.

15. Kass MA, Gordon MO, Gao F, et al. Delaying treatment of ocular hypertension: The Ocular Hypertension Treatment Study. Arch Ophthalmol 2010 Mar; 128(3):276-87.

16. Klein BE, Klein R, Linton KL. Intraocular pressure in an American community: The Beaver Dam Eye Study. Invest Ophthalmol Vis Sci 1999; 33: 2224-8.

17. Panchapakesan J, Mitchell P, Tumuluri K, et al. Five year incidence of cataract surgery: The Blue Mountain Eye Study. Br J Ophthalmol 2003 Feb; 87 (2): 168-72.

18. Rochtchina E, Mitchell P. Projected number of Australians with glaucoma in 2000 and 2030. Clin Experiment Ophthalmol 2000 Jun; 28(3): 146-8

19. Varma R, Wang D, Wu C, et al. Four-year incidence of open-angle glaucoma and ocular hypertension: The Los Angeles Latino Eye Study. Am J Ophthalmol 2012; 154:315-25.

20. Panday M, George R, Asokan R, et al. Six-year incidence of ocular hypertension in a South Indian population: The Chennai Eye Disease Incidence Study. Br J Ophthalmol 2015 May; 99 (5): 604-8.

21. Graham PA. Epidemiology of simple glaucoma and ocular hypertension. Br J Ophthalmol 1972; 56: 223-9.

22. Graham PA. The definition of pre-glaucoma. A prospective study. Trans Ophthalmol Soc UK 1969; 88:153-65.

23. Armaly MF. Ocular pressure and visual fields: A ten-year follow-up study. Arch Ophthalmol 1969 Jan; 81: 25-40.

24. Becker B, Morton WR. Topical epinephrine in glaucoma suspects. Am J Ophthalmol 1966; 62: 272-7.

25. Shin DH, Kolker AE, Kass MA, et al. Long-term epinephrine therapy of ocular hypertension. Arch Ophthalmol 1976; 94: 2059-60.

26. Kitazawa Y. Prophylactic therapy of ocular hypertension: A prospective study. Trans Ophthalmol Soc N Z 1981; 33: 30-2.

27. Epstein DL, Krug JH, Hertzmark E, et al. A long-term clinical trial of timolol therapy versus no treatment in the management of glaucoma suspects. Ophthalmology 1989; 96: 1460-7.
28. Kass MA, Gordon MO, Hoff MR, et al. Topical timolol administration reduces the incidence of glaucomatous damage in ocular hypertensive individuals: A randomized, double-masked long-term clinical trial. Arch Ophthalmol 1989; 107: 1590-8.

29. Norskov K. Routine tonometry in ophthalmic practice. II: Five-year follow-up. Acta Ophthalmol (Copenh) 1970; 48: 873-95.

30. David R, Livingston DG, Luntz MH. Ocular hypertension: A longterm follow-up of treated and untreated patients. Br J Ophthalmol 1977; 61: 668-74.

31. Chisholm IA, Stead S, Tan L, et al. Prognostic indicators in ocular hypertension. Can J Ophthalmol 1991; 98: 301-7.

32. Schulzer M, Drance SM, Douglas GR. A comparison of treated and untreated glaucoma suspects. Ophthalmology 1991; 98: 301-7.

33. Kass MA, Heuer DK, Higginbotham EJ, et al. The Ocular Hypertension Treatment Study: A randomized trial determines that topical ocular hypotensive medication delays or prevents the onset of primary open-angle glaucoma. Arch Ophthalmol. 2002; 120:701-13.

34. Gordon MO, Kass MA. The Ocular Hypertension Treatment Study: Design and baseline description of the participants. Arch Ophthalmol. 1999;117:573-83.

35. Gordon MO, Gao F, Beiser JA, et al. The 10-year incidence of glaucoma among patients with treated and untreated ocular hypertension. Arch Ophthalmol. 2011; 129: 1630-1.

36. Demirel S, DeMoraes CGV, Gardiner SK et al. The rate of visual field change in the Ocular Hypertension Treatment Study. Invest Ophthalmol Vis Sci 2012; 53: 224-7.

37. Keltner JL, Johnson CA, Quigg JM, et al Confirmation of visual field abnormalities in the Ocular Hypertension Treatment Study. Arch Ophthalmol 2000; 118:1187-94.

38. Keltner JL, Johnson CA, Cello KE, et al. Classification of visual field abnormalities in the Ocular Hypertension Treatment Study. Arch Ophthalmol 2003; 121:643-50.

39. De Moraes CGV, Demirel S, Gardiner SK et al. Effect of treatment on the rate of visual field change in the Ocular Hypertension Treatment Study observation group. Invest Ophthalmol Vis Sci 2012; 53:1704-9.

40. Stein JD, Talwar N, Laverne AM, et al. Trends in the use of ancillary glaucoma tests for patient with open-angle glaucoma from 2001 to 2009. Ophthalmology 2012 Apr; 119 (4): 748-58.

41. Zangwill LM, Weinreb RN, Berry CC, et al. The Confocal Scanning Laser Ophthalmoscopy Ancillary Study to the Ocular Hypertension Treatment Study: Study design and baseline factors. Am J Ophthalmol 2004;137:219-27.

42. Zangwill LM, Weinreb RN, Beiser JA, et al. Baseline topographic optic disc measurements are associated with the development of primary open angle glaucoma; The Confocal Scanning Laser Ophthalmoscopy Ancillary Study to the Ocular Hypertension Treatment Study. Arch Ophthalmol 2005;123:1188-97.

43. Weinreb RN, Zangwill LM, Jain S et al. Predicting the onset of glaucoma: The Confocal Scanning Laser Ophthalmoscopy Ancillary Study to the Ocular Hypertension Treatment Study. Ophthalmology 2010; 117:1674-83.

44. Zangwill LM, Jain S, Dirkes K et al. The rate of structural change: The Confocal Scanning Laser Ophthalmoscopy Ancillary Study to the Ocular Hypertension Treatment Study. Am J Ophthalmol 2013; 155:971-82.

45. Kuang TM, Zhang C, Zangwill LM, et al. Estimating the lead time gained by optical coherence tomography in detecting glaucoma before development of visual field defects. Ophthalmology 2015 Oct;122(10):2002-9.

46. Sommer A, Katz J, Quigley HA. Clinically detectable nerve fiber atrophy precedes the onset of glaucomatous field loss. Arch Ophthalmol 1991; 109:77-83.

47. Lisboa R, Leite MT, Zangwill LM, et al. Diagnosing preperimetric glaucoma with spectral domain optical coherence tomography. Ophthalmology 2012 Nov; 119 (11): 2261-9.

48. Colombo L, Bertuzzi F, Rulli E, et al. Correlations between the individual risk for glaucoma and RNFL and optic disc morphometrical evaluations in ocular hypertensive patients. $J$ Glaucoma 2016 May;25(5):e455-62.

49. Yalvac IS, Kulacoglu DN, Satana B, et al. Correlation between optical coherence tomography results and the scoring tool for assessing risk (STAR) score in patients with ocular hypertension. Eur $J$ Ophthalmol 2010 Nov-Dec; 20(6): 1018-25. 
50. Sugimoto M, Ito K, Goto R, et al. Symmetry analysis for detecting early glaucomatous changes in ocular hypertension using optical coherence tomography. Jpn J Ophthalmol. 2004 MayJun;48(3):281-6.

51. Mansoori T, Viswanath K, Balakrishna N. Quantification of retinal nerve fiber layer thickness in normal eyes, eyes with ocular hypertension, and glaucomatous eyes with SD-OCT. Ophthalmic Surg Lasers Imaging. 2010 Nov-Dec; 41 Suppl: S50-7

52. Kaushik S, Gyatsho J, Jain R, et al. Correlation between retinal nerve fiber layer thickness and central corneal thickness in patient with ocular hypertension: An optical coherence tomography study. Am J Ophthalmol 2006 May; 141(5):884-90.

53. Cellini M, Bernabini B, Carbonelli M, et al. Optical coherence tomography, frequency-doubling technology, and colour doppler imaging in ocular hypertension. Eye (Lond) 2007 Aug; 21 (8): 1071-7.

54. Halkiadakis I, Kipioti A, Emfietzoglous I, et al. Comparison of optical coherence tomography and scanning laser polarimetry in glaucoma, ocular hypertension, and suspected glaucoma. Ophthalmic Surg Lasers Imaging. 2008 Mar-Apr; 39 (2): 125-32.

55. Taliantzis S, Papaconstantinou D, Koutsandrea C, et al. Comparative studies of RNFL thickness measured by OCT with global index of visual fields in patients with ocular hypertension and early open angle glaucoma. Clin Ophthalmol 2009; 3:373-9.

56. Van Gestel A, Webers CA, Beckers HJ, et al. Ocular hypertension and the risk of blindness. J Glaucoma $2015 \mathrm{Jan} ; 24$ (1): 9-11.

57. Weinreb RN, Friedman DS, Fechtner RD et al. Risk assessment in the management of patients with ocular hypertension. Am J Ophthalmol 2004; 138: 458-67.

58. Gordon MO, Beiser JA, Brandt JD, et al. The Ocular Hypertension Treatment Study; baseline factors that predict the onset of primary open angle glaucoma. Arch Ophthalmol 2002 Jun;120(6):714-20; discussion 829-30.

59. AGIS Investigators. The Advanced Glaucoma Intervention Study (AGIS): 12. Baseline risk factors for sustained loss of visual field an visual acuity in patients with advanced glaucoma. Am J Ophthalmol 2002; 134: 499-512.

60. Pasquale LR, Kang JH, Manson JE, et al. Prospective study of type 2 diabetes mellitus and risk of primary open-angle glaucoma in women. Ophthalmology 2006; 113: 1081-6.

61. Mitchell P, Smith W, Chey T, et al. Open-angle glaucoma and diabetes: The Blue Mountains Eye Study. Ophthalmology 1997;104: 712-8.

62. Chopra V, Varma R, Francis B, et al. Type 2 diabetes mellitus and the risk of open-angle glaucoma: The Los Angeles Latino Eye Study Ophthalmology 2008; 115: 227-32.

63. Bonovas S, Peponis V, Filioussi K. Diabetes mellitus as a risk factor for primary open-angle glaucoma: A meta-analysis. Diabet Med 2004; 21: 609-14.

64. Gordon MA, Beiser JA, Kass MA. Is a history of diabetes mellitus protective against developing primary open-angle glaucoma? Arch Ophthalmol 2008; 126:280-1.

65. Tielsch JM, Sommer A, Katz J, et al. Racial variations in the prevalence of primary open-angle glaucoma. The Baltimore Eye Survey. JAMA 1991; 266: 369-74.

66. Leske MC, Connell AM, Wu SY, et al. Incidence of open-angle glaucoma: The Barbados Eye Studies. The Barbados Eye Studies Group. Arch Ophthalmol 2001; 119: 89-95.

67. Leske MC, Connell AM, Schachat AP, et al. The Barbados Eye Study. Prevalence of open angle glaucoma. Arch Ophthalmol 1994; 112: 8219 .

68. Budenz DL, Barton K, Whiteside-de Vos J, et al. Prevalence of glaucoma in an urban West African population: The Tema Eye Survey. JAMA Ophthalmol 2013; 131: 651-8.

69. Deol M, Taylor D, Radcliffe NM. Corneal hysteresis and its relevance to glaucoma. Curr Opin Ophthalmol 2015, 26: 96-102.

70. Pensyl D, Sullivan-Mee M, Torres-Monte M, et al. Combining corneal hysteresis with central corneal thickness and intraocular pressure for glaucoma risk assessment. Eye 2012;26, 1349-56

71. Mangouritsas G, Morphis G, Mourtzoukos S, et al. Association between corneal hysteresis and central corneal thickness in glaucomatous and nonglaucomatous eyes. Acta Ophthalmol 2009; 87:901-5

72. Kaushik S, Pandav SS, Banger A, et al. Relationship between corneal biomechanical properties, central corneal thickness, and intraocular pressure across the spectrum of glaucoma. Am J Ophthalmol 2012; 153:840-9.
73. Congdon NG, Broman AT, Bandeen-Roche K, et al. Central corneal thickness and corneal hysteresis associated with glaucoma damage. Am J Ophthalmol 2006; 141:868-75.

74. Medeiros FA, Meira-Freitas D, Lisboa R, et al. Corneal hysteresis as a risk factor for glaucoma progression: A prospective longitudinal study. Ophthalmology 2013; 120:1533-40.

75. De Moraes CV, Hill V, Tello C, et al. Lower corneal hysteresis is associated with more rapid glaucomatous visual field progression. $J$ Glaucoma 2012; 21:209-13.

76. Chee RI, Silva FQ, Ehrlich JR, et al. Agreement of flicker chronoscopy for structural glaucomatous progression detection and factors associated with progression. Am J Ophthalmol 2013; 155:983-90.

77. Sun L, Shen M, Wang J, et al. Recovery of corneal hysteresis after reduction of intraocular pressure in chronic primary angle-closure glaucoma. Am J Ophthalmol 2009; 147:1061-6.

78. Agarwal DR, Ehrlich JR, Shimmyo M, et al. The relationship between corneal hysteresis and the magnitude of intraocular pressure reduction with topical prostaglandin therapy. Br J Ophthalmol 2012 96:254-7.

79. Wells AP, Garway-Heath DF, Poostchi A, et al. Corneal hysteresis but not corneal thickness correlates with optic nerve surface compliance in glaucoma patients. Invest Ophthalmol Vis Sci 2008; 49: 3262-8.

80. Sullivan-Mee M, Billingsley SC, Patel AD, et al. Ocular response analyzer in subjects with and without glaucoma. Optom Vis Sci 2008; 85:463-70.

81. Anand A, De Moraes CG, Teng CC, et al. Corneal hysteresis and visual field asymmetry in open angle glaucoma. Invest Ophthalmol Vis Sci 2010; 51:6514-8.

82. Narayanaswamy A, Su DH, Baskaran M, et al. Comparison of ocular response analyzer parameters in Chinese subjects with primary angle-closure and primary open-angle glaucoma. Arch Ophthalmol 2011; 129:429-34.

83. Morita T, Shoji N, Kamiya K, et al. Corneal biomechanical properties in normal tension glaucoma. Acta Ophthalmol 2012; 90:e48-e53.

84. Ayala M. Corneal hysteresis in normal subjects and in patients with primary open-angle glaucoma and pseudoexfoliation glaucoma. Ophthalmic Res 2011; 46:187-91.

85. Ozkok A, Tamcelik N, Ozdamar A, et al. Corneal viscoelastic differences between pseudoexfoliative glaucoma and primary open-angle glaucoma. J Glaucoma 2013; 22:740-5.

86. Kirwan C, O'Keefe M, Lanigan B. Corneal hysteresis and intraocular pressure measurement in children using the Reichert ocular response analyzer. Am J Ophthalmol 2007; 144:642.

87. Suh MH, Park KH. Pathogenesis and clinical implications of optic disk hemorrhage in glaucoma. Surv Ophthalmol. 2014 Jan-Feb;59(1): 19-29.

88. Healey PR, Mitchell P, Smith W, et al. Optic disc hemorrhages in a population with and without signs of glaucoma. Ophthalmology 1998; 105:216-23.

89. Uhler TA, Piltz-Seymour J. Optic disc hemorrhages in glaucoma and ocular hypertension: Implications and recommendations. Curr Opin Ophthalmol 2008 Mar; 19(2):89-94.

90. Budenz DL, Anderson DR, Feuer WJ, et al. Detection and prognostic significance of optic disc hemorrhages during the Ocular Hypertension Treatment Study. Ophthalmology. 2006 Dec; 113(12): 2137-43.

91. Leske MC, Heijl A, Hussein M et al. Factors for glaucoma progression and the effect of treatment: The Early Manifest Glaucoma Trial. Arch Ophthalmol 2003; 121: 48-56.

92. Suh $\mathrm{MH}$, Park KH. Period prevalence and incidence of optic disc haemorrhage in normal tension glaucoma and primary open-angle glaucoma. Clin Experiment Ophthalmol 2011 Aug;39(6):513-9.

93. De Moraes CG, Demirel S, Gardiner SK, et al. Rate of visual field progression in eyes with optic disc hemorrhages in the Ocular Hypertension Treatment Study. Arch Ophthalmol 2012;130:1541-6.

94. Coleman AL, Gordon MO, Beiser JA, et al. Baseline risk factors for the development of primary open-angle glaucoma in the Ocular Hypertension Treatment Study. Am J Ophthalmol 2004;138:684-5.

95. Medeiros FA, Weinreb RN, Sample PA. Validation of a predictive model to estimate the risk of conversion from ocular hypertension to glaucoma. Arch Ophthalmol. 2005;123:1351-60.

96. Gordon MO, Torri V, Miglior S, et al. Validated prediction model for the development of primary open angle glaucoma in individuals with ocular hypertension. Ophthalmology 2007 January;114(1):10-9. 
97. Takwoingi Y, Botello AP, Burr JM, et al. External validation of the OHTS-EGPS model predicting the 5-year risk of open-angle glaucoma in ocular hypertensives. Br J Ophthalmol 2014 Mar;98(3):309-14.

98. The Ocular Hypertension Study Group and the European Glaucoma Prevention Study Group. The accuracy and clinical application of predictive models for primary open-angle glaucoma in ocular hypertensive individuals. Ophthalmology 2008; 115:2030-6.

99. Miglior S, Zeyen T, Pfeiffer N, et al. The European Glaucoma Prevention Study design and baseline description of the participants. Ophthalmology 2002 Sep; 109(9): 1612-21.

100. Miglior S, Pfeiffer N, Torri V, et al. Predictive factors for open-angle glaucoma among patients with ocular hypertension in the European Glaucoma Prevention Study. Ophthalmology 2007. Jan; 114(1):3-9.

101. Jampel H, Boland MV. Calculating the "threshold to treat" in ocular hypertension. J Glaucoma 2014 Oct-Nov;23(8):485-6.

102. Bagga H, Liu JH, Weinreb RN. Intraocular pressure measurements throughout the 24h. Curr Opin Ophthalmol 2009 Mar; 20(2): 79-83.

103. Mosaed S, Liu JH, Weinreb RN. Correlation between office and peak nocturnal intraocular pressures in healthy subjects and glaucoma patients. Am J Ophthalmol 2005;139:320-4.

104. Mosaed S, Chamberlain WD, Liu JH, et al. Association of central corneal thickness and 24-hour intraocular pressure fluctuation. $J$ Glaucoma. 2008;17:85-8.

105. Jonas J, Budde W, Stroux A, et al. Single intraocular pressure measurement and diurnal intraocular pressure profiles. Am J Ophthalmol 2005; 139:1136-7.

106. Grippo TM, Liu JHK, Zebardast N, et al. Twenty-four hour pattern of intraocular pressure in untreated patients with ocular hypertension. Invest Ophthalmol Vis Sci 2013;54:512-7.

107. Okafor KC, Brandt JD. Measuring intraocular pressure. Curr Opin Ophthalmol 2015, 26:103-9.

108. Bhorade AM, Gordon MO, Wilson B, et al. Variability of intraocula pressure measurements in observation participants in the Ocular Hypertension Treatment Study. Ophthalmology 2009;116:717-24.

109. Sandhu SS, Chattopadhyay S, Birch MK, et al. Frequency of Goldmann applanation tonometer calibration error checks. J Glaucoma 2005; 14(3): 215-8.

110. Chuo JY, Mikelberg FS. Calibration errors of Goldmann tonometer in a tertiary eye care centre. Can J Ophthalmol 2007; 42(5): 712-4.

111. Choudhari NS, George R, Baskaran M, et al. Measurement of Goldmann applanation tonometer calibration error. Ophthalmology 2009; 116(1): 3-8.

112. Kumar N, Jivan S, Batterbury M. Tonometer calibration. Ophthalmology 2009; 116(12): 2480-1.

113. Brandt JD. The myth of clinical precision. Ophthalmology 2009; 116(1): 1-2 el.

114. Turner MJ, Graham SL, Avolio AP, et al. Potential effects of systematic errors in intraocular pressure measurements on screening for ocular hypertension. Eye 2013; 27, 502-6.

115. Rotchford AP, Uppal S, Lakshmanan A, et al. Day-to-day variability in intraocular pressure in glaucoma and ocular hypertension. $\mathrm{Br} J$ Ophthalmol 2012 Jul;96(7):967-70.

116. Rotchford AP, King AJ. Repeatability of measurements of effectiveness of glaucoma medication. Br J Ophthalmol $2012 \mathrm{Dec}$ Dec;96(12):1494-7.

117. Realini T, Barber L, Burton D. Frequency of asymmetric intraocular pressure fluctuations among patients with and without glaucoma. Ophthalmology 2002;109:1367-71.

118. Realini T, Weinreb N, Wisniewski S. Short-term repeatability of diurnal intraocular pressure patterns in glaucomatous individuals. Ophthalmology 2011; 118:47-51.

119. Realini T. Assessing the effectiveness of intraocular pressure-lowering therapy. Ophthalmology 2010 Nov;117(11):2045-6.

120. Sit AJ. Intraocular pressure variations: Causes and clinical significance. Can J Ophthalmol 2014 Dec;49(6):484-8.

121. Mansberger SL, Cioffi GA. The probability of glaucoma from ocular hypertension determined by ophthalmologists in comparison to a risk calculator. J Glaucoma 2006 Oct; 15(5):426-31.

122. Boland MV, Quigley HA, Lehmann HP. The impact of physician subspecialty training, risk calculation, and patient age on treatment recommendations in ocular hypertension. Am J Ophthalmol 2011;152:638-45.

123. Song C, De Moraes CG, Forchheimer I, et al. Risk calculation variability over time in ocular hypertensive subjects. J Glaucoma. 2014 Jan;23(1): 1-4.
124. Hollands H, Kertes PJ. Measuring the size of a treatment effect: Relative risk reduction, absolute risk reduction, and number needed to treat. In: Irwig L, Irwig J, Trevena L, et al., eds. Smart Health Choices: Making Sense Of Health Advice. London: Hammersmith Press; 2008. Ch 18. 213-6.

125. Coleman AL, Singh K, Wilson R, et al. Applying an evidence-based approach to the management of patients with ocular hypertension: Evaluating and synthesizing published evidence. Am J Ophthalmol 2004; 138:S3-S10.

126. Higginbotham EJ. Treating ocular hypertension to reduce glaucoma risk; when to treat. Drugs 2006; 66(8): 1033-9.

27. McQuay HJ, Moore RA. Using numerical results from systematic reviews in clinical practice. Ann Intern Med 1997;126:712-20.

128. Brugts JJ, Yetgin T, Hoeks SE, et al. The benefits of statins in people without established cardiovascular disease but with cardiovascular risk factors: Meta-analysis of randomized controlled trials. BMJ 2009 Jun 30; 338:b2376.

129. Gold MR, Siegel JE, Russell LB, et al. Cost-effectiveness in Health and Medicine. New York, NY: Oxford University Press; 1996:425.

130. Boland MV, Quigley HA, Lehmann HP. The impact of risk calculation on treatment recommendations made by glaucoma specialists in cases of ocular hypertension. J Glaucoma 2008 Dec; 17(8): 631-8.

131. Kymes SM, Plotzke MR, Kass MA, et al. Effect of patient's life expectancy on the cost-effectiveness of treatment for ocular hypertension. Arch Ophthalmol 2010;128(5):613-8.

132. Damji KF, Behki R, Wang L. Canadian perspectives in glaucoma management: Setting target intraocular pressure range. Can J Ophthalmol 2003;38:189-97.

133. Singh K, Shrivastava A. Early aggressive intraocular pressure lowering, target intraocular pressure, and a novel concept for glaucoma care. Surv Ophthalmol 2008 Nov;53 Suppl 1:S33-8.

134. Goldberg I. Stepping up glaucoma management: When and how? Open Ophthalmol J 2009;3:117-22.

135. Coleman AL, Caprioli J. The logic behind target intraocular pressure. Am J Ophthalmol 2009 Mar;147(3): 379-80.

136. Canadian Ophthalmological Society Cataract Surgery Clinical Practice Guideline Expert Committee. Canadian Ophthalmological Society evidence-based clinical practice guidelines for the management of glaucoma in the adult eye. Can J Ophthalmol 2009;44 Suppl 1:S7-93.

137. Mansberger SL, Hughes BA, Gordon MO, et al. Comparison of initial intraocular pressure response with topical B-adrenergic antagonists and prostaglandin analogues in African American and White individuals in the Ocular Hypertension Treatment Study. Arch Ophthalmol 2007; 125:454-9.

138. Medeiros FA, Weinreb RN, Zangwill LM, et al. Long-term intraocular pressure fluctuations and risk of conversion from ocular hypertension to glaucoma. Ophthalmology 2008 Jun;115(6):934-40.

139. Wong MO, Lee JW, Choy BN, et al. Systematic review and metaanalysis on the efficacy of selective laser trabeculoplasty in openangle glaucoma. Surv Ophthalmol 2015 Jan-Feb; 60(1):36-50.

140. Shazly TA, Latina MA, Dagianis JJ, et al. Effect of central corneal thickness on the long-term outcome of selective laser trabeculoplasty as primary treatment for ocular hypertension and primary open-angle glaucoma. Cornea 2012 Aug;31(8):883-6.

141. Lee R, Hutnik CM. Projected cost comparison of selective laser trabeculoplasty versus glaucoma medication in the Ontario Health Insurance Plan. Can J Ophthalmol 2006 Aug;41(4):449-56.

142. Seider MI, Keenan JD, Han Y. Cost of selective laser trabeculoplasty vs topical medication for glaucoma. Arch Ophthalmol 2012 Apr;130(4): 529-30.

143. Stein JD, Kim DD, Peck WW, et al. Cost-effectiveness of medications compared with laser trabeculoplasty in patients newly diagnosed with open-angle glaucoma. Arch Ophthalmol 2012 Apr;130(4):497-505 